\title{
Integração "ensino-serviço" no processo de mudança na formação profissional em Odontologia
}

Mirelle Finkler ${ }^{1}$

João Carlos Caetano²

Flávia Regina Souza Ramos ${ }^{3}$

FINKLER, M.; CAETANO, J.C.; RAMOS, F.R.S. Teaching-service integration in the change process in Dentistry training. Interface - Comunic., Saude, Educ., v.15, n.39, p.1053-67, out./dez. 2011.

This study aims to evaluate the integration of dentistry courses with the public health services network. The collected data were used with a qualitative methodology in a case study in which 15 courses participated, and were articulated to a theoretical framework for the analysis of changes in the undergraduate courses. According to this framework, the actual 'teachingservice' integration is conceived as 'teaching, management, care and social control'. The results indicate imprecision regarding this theme, associations with the healthcare system that cannot be characterized as effective integration, and the practically nonexistent integration of teaching-care-management-social control, or at best, a process which is incipient and under construction, with gaps. Thus, it can be concluded that, overall, Brazilian dentistry courses need to improve in terms of the alliances and strategic actions based on permanent health education, so that the new curricular changes can effectively cooperate with the SUS (Brazil's National Health System).

Keywords: Teaching-care integration services. Higher education. Teaching. Dentistry courses. Dental staff.
Este trabalho analisa como ocorre a integração dos cursos de Odontologia com a rede pública de saúde. Para tanto, tomam-se os dados coletados em um estudo de caso do qual participaram 15 cursos, articulando-os a um referencial teórico para análise das mudanças na graduação, no qual a integração "ensino-serviço" é concebida de forma ampliada como "ensino, gestão, atenção e controle social". Os resultados indicam uma imprecisão sobre o tema, vínculos com o sistema de saúde não caracterizáveis como integração efetiva, e a praticamente inexistente integração ensino - atenção - gestão controle social, ou no máximo, um processo incipiente e em construção, com lacunas na articulação com a gestão dos serviços e o controle social. Conclui-se que os cursos precisam avançar em muito nas alianças e ações estratégicas com base na educação permanente em saúde, a fim de que as novas mudanças curriculares sejam efetivamente capazes de colaborar com o aperfeiçoamento do SUS.

Palavras-chave: Serviços de integração docente-assistencial. Educação superior. Ensino. Escolas de Odontologia. Recursos humanos em Odontologia.
${ }^{1}$ Departamento de Odontologia, Centro de Ciências da Saúde, Universidade Federal de Santa Catarina (CCS/ UFSC). Campus Universitario Reitor João David Ferreira Lima,Trindade, Florianópolis, SC, Brasil. 88.040-970. mirellefinkler@yahoo.com.br ${ }^{2}$ Departamento de Saúde Pública, CCS/UFSC. ${ }^{3}$ Departamento de Enfermagem, CCS, UFSC. 


\section{A integração "ensino-serviço" no contexto das Diretrizes Curriculares Nacionais}

Há um consenso na literatura da educação de profissionais da saúde quanto à hegemonia do paradigma biologicista, centralizado no profissional e nas técnicas. Este modelo pedagógico hegemônico, centrado em conteúdos compartimentados e isolados, que fragmentam o ser humano em especialidades, dissociando os conhecimentos das áreas básicas e clínicas, foca o ensino-aprendizagem no espaço da prática hospitalar e clínica, medicaliza o social, orienta para o mercado, incentiva a especialização precoce e a incorporação tecnológica, a partir de bases pedagógicas tradicionais, perpetuando, assim, o modelo vigente e ineficiente de práticas em saúde (Ramos, Padilha, 2006; Brasil, 2004).

Por estas razões, organizações docentes e estudantis constituíram movimentos organizados na produção de melhores caminhos para a transformação dos cursos em saúde (Brasil, 2004). Estes movimentos contribuíram com a elaboração das Diretrizes Curriculares Nacionais (DCNs), que devem ser compreendidas dentro do contexto da Reforma Sanitária Brasileira (Morita, Kriger, 2004). A publicação destas diretrizes é um dos indicativos do atual momento de mudanças no entrecruzamento dos mundos da saúde e da educação e da visibilidade da formação profissional como política pública prioritária (Ramos, Padilha, 2006).

No sentido de tornar o SUS uma rede de ensino-aprendizagem na prática do trabalho, algumas das estratégias implementadas incluíram: a Política Nacional de Educação Permanente em Saúde, o Programa Aprender SUS, a Residência Multiprofissional em Saúde (Brasil, 2004) e o Programa Nacional de Reorientação da Formação Profissional em Saúde, que passou a incentivar transformações nos processos de formação, com base na reorientação teórica, nos cenários de prática (integração docenteassistencial, diversificação dos cenários e articulação dos serviços assistenciais com o SUS) e na reorientação pedagógica (Brasil, 2005). Embora estas estratégias estejam proporcionando avanços significativos, especialmente na Enfermagem e na Medicina, em relação à Odontologia, percebe-se um atraso histórico nestes movimentos de mudança (Morita, Kriger, 2004).

Em qualquer área, formar profissionais com perfil adequado significa propiciar a capacidade de aprender a aprender, de trabalhar em equipe, de comunicar-se, de refletir criticamente e de aprimorar qualidades humanistas. Na discussão mais específica em Odontologia, ressalta-se a importância, também, da inserção precoce do graduando em seu contexto profissional, das clínicas integradas de complexidade crescente, da melhoria na formação em Saúde Coletiva e da diversificação dos cenários de aprendizagem (Morita, Kriger, 2004), bem como um cuidado com a formação ético-humanista dos envolvidos (Finkler, 2009).

Estas demandas encontram, na integração "ensino-serviço" (IES), um lócus privilegiado para a reflexão sobre a realidade da produção de cuidados e a necessidade de transformação do modelo assistencial vigente, tecnocentrado, para um modelo que considere como central as necessidades dos usuários (Albuquerque et al., 2008).

A IES pode ser definida como o trabalho coletivo, pactuado e integrado de estudantes e professores da saúde com trabalhadores dos serviços e seus gestores, visando à qualidade da atenção à saúde, da formação profissional e ao desenvolvimento dos trabalhadores dos serviços. Seria, portanto, um elemento em si mesmo constitutivo de uma nova maneira de pensar a formação, não se tratando de transformar o espaço dos serviços e comunidade em extensões dos hospitais e das clínicas dos cursos, mas sim, de construir espaços de aprendizagem com a incorporação de docentes e estudantes à produção de serviços em cenários reais. Assim, os docentes constituiriam parte dos serviços e os profissionais dos serviços seriam corresponsáveis pela formação acadêmica (Albuquerque et al., 2008).

Não é possível pensar a mudança da formação profissional sem a discussão sobre a IES, até por ser uma estratégia fundamental para a consolidação do SUS. Sob o marco legal, os dois setores - saúde e educação - legítima e legalmente devem ocupar-se da formação na área, de forma articulada, promovendo a cooperação técnica entre os respectivos Ministérios (Haddad et al., 2006) e submetendo as principais decisões à participação popular (Brasil, 2004).

Uma avaliação em relação às mais recentes mudanças dos cursos de Odontologia indicou que a

aderência média das graduações às DCNs foi de 77\% (regular). Entre as características de um grupo de faculdades com menor aderência, observou-se a ausência da integração com a rede de serviços e 
projetos político-pedagógicos (PPPs), redigidos de forma a reproduzirem parte das DCNs, mas sem haver uma correspondência com as realidades observadas. Já nos cursos com maior aderência, verificouse uma maior diversificação dos cenários de ensino, considerados essenciais para o desenvolvimento do perfil profissional voltado para o SUS, uma vez que é no mundo do trabalho que devem acontecer as maiores experiências educativas (Haddad et al., 2006). Entre outras dificuldades - como as de integração curricular, de desenvolver PPPs inovadores, de estabelecer interdisciplinaridade, de formar para um perfil generalista com corpo docente especializado -, observou-se a dificuldade em se utilizar a rede de serviços como espaço de aprendizagem e em estabelecer parcerias para estágios supervisionados (Haddad et al. 2006).

Neste contexto, instituiu-se o Programa de Educação pelo Trabalho para a Saúde (PET-Saúde), que, de 2009 a 2011, fomentará grupos de aprendizagem tutorial no âmbito da Estratégia Saúde da Família (ESF), viabilizando o aperfeiçoamento e especialização em serviço dos profissionais, bem como a iniciação ao trabalho e estágios, aos estudantes, de acordo com as necessidades do SUS (Brasil, 2008). Pretende-se, assim, avançar no processo de IES, à medida que se reconhece e valoriza o papel dos profissionais da rede, com o respaldo do professor tutor, oriundo da universidade (Brasil, 2007).

Há, portanto, um momento de políticas públicas favoráveis para que o SUS seja, de fato, considerado o interlocutor essencial na formulação e implementação dos PPPs, para o que as DCNs assumem um papel estratégico no seu aperfeiçoamento (Morita, Kriger, 2004):

A formação do cirurgião-dentista deverá contemplar o sistema de saúde vigente no país, a atenção integral da saúde no sistema regionalizado e hierarquizado de referência e contrareferência e o trabalho em equipe [...] de forma articulada ao contexto social, entendendo-a como uma forma de participação e contribuição social. (Brasil, 2002, p.10)

Estas diretrizes podem ser alcançadas à medida que os cursos de graduação construam e implementem PPPs tendo a integração ensino-serviço como um elemento central do processo de reestruturação da formação profissional. Mas isto tem acontecido? De que forma? O objetivo deste trabalho consiste em compreender a valorização que os cursos de Odontologia brasileiros têm atribuído à IES como uma estratégia capaz de potencializar mudanças na formação profissional, bem como identificar como esta integração tem sido realizada, encaminhando reflexões que buscam cooperar com os atuais desafios à formação de um novo perfil profissional.

Antes ainda, é necessário resgatar algumas referências teóricas do campo das mudanças na formação de profissionais de saúde, no sentido de possibilitar a análise da IES nos novos currículos e práticas de formação.

Para Feuerwerker (2002), transformar a formação profissional exige mudanças profundas que implicam alterações não apenas de concepções e práticas, mas também de relações de poder nas universidades, nos serviços de saúde e no campo das políticas. A base destas propostas é a democratização, com a construção de espaços de poder amplamente compartilhados, o que requer a articulação estratégica de grupos que acumulam poder e conhecimento, que são capazes de refletir criticamente e que, ao associarem heterogeneidades organizadas e construírem canais de comunicação e discussão coletiva, ganham potência em suas ações.

Almeida (1999) representou, em três planos de profundidade, as mudanças na formação de médicos, que podem ser aplicados às mudanças na formação dos demais profissionais da saúde. No primeiro plano o autor situou as mudanças superficiais, geralmente pontuais e parciais, onde as inovações atingem as atividades, os meios e as relações técnicas entre os agentes de ensino e o processo de ensino. Essas mudanças produzem alterações isoladas de conteúdos, ou de relações, ou de processos. É o plano quantitativo, que pode conduzir a mudanças do tipo "inovação". No segundo plano estão as mudanças mais abrangentes que passam pela reinterpretação das bases conceituais da educação profissional, tendo como resultados alterações nas relações sociais durante a formação acadêmica. É o plano qualitativo, que pode conduzir a mudanças do tipo "reforma". No terceiro plano, situam-se as alterações que buscam introduzir uma nova ordem no processo de produção de profissionais e nas suas relações com a estrutura socioeconômica, englobando toda a sociedade e o seu 
contexto. Resultam em alterações gerais dos conteúdos, dos processos e das relações, implicando: a substituição da prática profissional, desenvolvimento de tecnologia apropriada, articulação biopsicossocial, intersetorialidade e superação da dissociação entre estudo, trabalho e controle social. É o plano da relevância, capaz de conduzir a mudanças do tipo "transformação".

Utilizando esse esquema de Almeida (1999), Feuerwerker (2002) acrescenta que tais planos implicam, também, a utilização de referenciais teórico-conceituais diferentes quanto à educação e à saúde: o primeiro plano corresponderia à concepção tradicional de educação e à biologicista em saúde, predominando a reprodução das práticas hegemônicas; o segundo corresponderia à concepção humanista (libertária) da educação e ao conceito ampliado de saúde, buscando-se alternativas às práticas hegemônicas por meio das práticas de reflexão crítica e proporcionando uma democratização nas relações; enquanto o terceiro corresponderia à concepção pedagógica crítica-reflexiva e ao pensamento estratégico em saúde, visando à constituição de sujeitos, à busca de práticas transformadoras e à incorporação de outros sujeitos sociais ao processo de educação e de saúde.

No mesmo sentido, Lampert (2002) elaborou uma tipologia da implementação de mudanças nos currículos de graduação médica, variando de um perfil tradicional, inovador com tendência tradicional, inovador com tendência avançada, até um perfil avançado, respectivamente e gradualmente correspondentes ao modelo hegemônico de formação em saúde (flexneriano) até o paradigma da integralidade. Ao analisar algumas escolas médicas, a autora observou, em todas, alguma iniciativa de inovação recente, mesmo na de tipologia tradicional, sendo que as com reformas curriculares de tipologia avançada, decorrentes de propostas recentes, ainda não totalmente consolidadas. De estudos como este, advém a constatação de que a formação em saúde passa por mudanças em direção às transformações desejadas, ainda que a tendência de inovação seja carente de tempo e de forte apoio reflexivo, acompanhamento e avaliação, pois muitas dessas mudanças vão de encontro à política neoliberal e à cultura voltada para a doença.

Os resultados encontrados por Finkler (2009) na análise das mudanças curriculares nos cursos de Odontologia vão ao encontro dos obtidos por Lampert (2002), destacando-se dentre os principais avanços: a valorização da formação dos professores, a preocupação com o desenvolvimento de profissionais capacitados a atuar nos serviços públicos, a integração do currículo acadêmico e o desenvolvimento de competências profissionalizantes precocemente. Por outro lado, os atrasos mais evidentes relacionaram-se: à pequena valorização da formação humanística, cultural e política dos estudantes, à orientação didática e aos cenários de ensino-aprendizagem, bem como à ausência de tutoria e da avaliação somativa, por conta dos pressupostos e métodos ainda bastante tradicionais do processo educativo. Já o enfoque teórico dos cursos e sua integração com os serviços públicos, embora com indícios de alguns avanços, foram identificados como fragilidades, sinalizando alguns dos desafios que as mudanças curriculares em Odontologia precisam assumir ${ }^{4}$.

Vale ainda resgatar o "quadrilátero da formação para a área da saúde" de Ceccim e Feuerwerker (2004), que concebe a questão específica da IES ou "ensino - serviço - comunidade" de forma ampliada ao considerar os quatro elementos que tomam parte neste processo: ensino, gestão, atenção e controle social. Isto porque o componente "serviço" não pode ser restrito à noção de práticas de atenção, mas deve revelar uma estrutura de condução das políticas, a gerência do sistema e organização de conhecimentos do setor. O componente "comunidade" deve conter algo além da interação com a população, envolvendo

\footnotetext{
${ }^{4}$ Em trabalho prévio, analisou-se a formação ética dos estudantes de Odontologia no Brasil, a partir de coleta de dados sobre os múltiplos fatores que tomam parte neste processo e que vão desde o perfil teórico dos cursos e as diversas questões referentes à abordagem pedagógica até as questões mais diretamente relacionadas à abordagem ética (Finkler, 2009). Este estudo, por sua vez, toma alguns daqueles dados, a fim de discutir em profundidade a questão específica da IES não como mais um elemento da formação ético-pedagógica, mas como um dos elementoschave para redefinir o perfil do egresso acadêmico, à luz das DCNs.
} 
a noção de relevância e responsabilidade social do ensino, aberto à interferência de sistemas de avaliação, regulação pública e estratégias de mudança que envolvem o controle social. No componente "ensino", além do reconhecimento dos papéis de dirigentes e docentes, destaca-se a articulação com o movimento estudantil como ator político das instituições formadoras. Essa imagem de um quadrilátero se propõe à construção e organização de uma gestão da educação na saúde integrante da gestão do sistema de saúde, redimensionando a imagem dos serviços e valorizando o controle social. Pode, assim, ser um instrumento útil para a análise das mudanças em curso na formação profissional em saúde.

\section{Procedimentos metodológicos}

Este estudo exploratório descritivo empregou a abordagem qualitativa por ser considerada a mais adequada à compreensão de fenômenos específicos e delimitáveis mais pelo seu grau de complexidade interna do que por sua expressão quantitativa.

Os cursos participantes foram selecionados de modo a compor uma amostra da sua distribuição nacional, em termos de proporção entre cursos públicos e privados (30\% e $70 \%$, respectivamente), e de localização, por regiões geográficas (70\% no sul e sudeste e $30 \%$ nas demais regiões), totalizando 15 cursos.

A coleta de dados foi iniciada após a aprovação ética do projeto de pesquisa, consistindo de três etapas: na primeira, um questionário ${ }^{5}$ foi enviado aos

${ }^{5}$ Utilizou-se como modelo o questionário construído por Lampert (2002, p.275-279) coordenadores dos cursos, sendo que cada questão possuía três possíveis afirmações, dentre as quais deveriam eleger a que mais se assemelhava à experiência predominantemente vivenciada no curso. De um modo em geral, estas afirmações foram elaboradas pensando-se em três situações distintas que caracterizariam o processo de mudanças curriculares, paralelas ao modelo de ensino que desenvolvem: desde o mais tradicional, hegemônico, nos moldes flexnerianos (respostas A), passando pelo inovador (respostas B), em direção ao mais avançado, a caminho de reformas transformadoras na construção do paradigma da integralidade (respostas $C$ ) (Lampert, 2002, p.171). Neste trabalho, recortam-se as três questões diretamente relacionadas ao objeto aqui em foco, conforme apresentado no Quadro 1.

A partir dos primeiros resultados, a segunda etapa pôde ser iniciada, buscando-se um aprofundamento da análise das experiências dos dois cursos de resultados mais diferenciados entre si quanto à IES. Solicitaram-se, às instituições selecionadas, documentos tais como o PPP e o currículo, que permitiram uma aproximação do arcabouço teórico-metodológico dos cursos.

Na terceira etapa, buscou-se uma aproximação mais concreta com a realidade acadêmico-pedagógica, por meio de entrevistas semidirigidas, observação direta de atividades acadêmicas e grupos focais, que permitiram a triangulação dos dados. Em todas estas estratégias, a amostragem foi delimitada pelo critério de saturação dos dados.

Uma vez transcritas as falas das entrevistas e dos grupos focais e agrupadas as informações registradas no diário de campo, os dados coletados foram: (1) ordenados, (2) categorizados, (3) reordenados de acordo com as categorias iniciais gerando categorias temáticas, e, por fim, (4) analisados a partir da interpretação destas categorias, à luz das referências teóricas pertinentes. 
Quadro 1. Questões do questionário empregado mais relacionadas à integração "ensino-serviço"

1. PERFIL DO EGRESSO - Esta Escola predominantemente...

a) forma cirurgiões-dentistas com perfil liberal e generalista, com acentuada ênfase no uso de tecnologias e na importância da especialização para o mercado de trabalho

b) forma cirurgiões-dentistas com perfil generalista, orientados para a competitividade do mercado de trabalho liberal e com algum preparo para trabalhar no setor público, segundo os princípios do SUS

c) forma cirurgiões-dentistas com um perfil generalista, humanista, autônomo, crítico e reflexivo, familiarizados com os serviços de saúde (SUS) e capacitados a atuar de acordo com as necessidades da sociedade, segundo os princípios do SUS

Justificativa:

Evidência(s):

2. ENFOQUE TEÓRICO - Esta Escola predominantemente...

a) ministra o curso sob enfoque biomédico/clínico

b) ministra o curso buscando um equilíbrio no enfoque biológico e no social

c) ministra o curso sob enfoque epidemiológico, enfatizando os processos sociais na determinação dos fenômenos de saúde-doença

Justificativa:

Evidência(s):

3. INTEGRAÇÃO COM OS SERVIÇOS DE SAÚDE - Esta Escola predominantemente...

a) tem corpo docente que não participa dos serviços de saúde (SUS) e do seu planejamento na sua área de influência, assim como os dentistas dos serviços também não participam na docência

b) tem docentes que participam esporadicamente dos serviços e do planejamento do sistema de saúde público e profissionais dos serviços que eventualmente participam na docência

c) tem serviços docentes-assistenciais integrados com o sistema de saúde público, sendo que seus docentes participam do planejamento e da avaliação do sistema em sua área de influência

Justificativa:

Evidência(s):

\section{Um panorama da integração "ensino-serviço" nos cursos de Odontologia brasileiros}

As respostas fornecidas em cada questão foram agrupadas e classificadas (Tabela 1) de acordo com o perfil dos cursos com relação ao processo de mudanças curriculares que vêm desenvolvendo e conforme o referencial teórico-metodológico adotado.

Os dados demonstram que apenas dois coordenadores consideraram que o perfil dos egressos de seus cursos ainda é o tradicional, no qual o profissional é formado para um mercado de trabalho basicamente liberal, com alta valorização das especializações clínicas. Possivelmente, as mudanças recentes no trabalho em saúde (implantação das Equipes de Saúde Bucal na ESF e dos Centros de

Tabela 1. Somatórios das respostas dos coordenadores dos 15 cursos participantes, classificados por questão e de acordo com o perfil dos cursos com relação ao processo de mudanças curriculares

\begin{tabular}{lccc}
\hline \multicolumn{1}{c}{ Questão/perfil } & Tradicional (resposta A) & Inovador (resposta B) & Avançado (resposta C) \\
\hline 1. Perfil do egresso & 2 & 6 & 7 \\
2. Enfoque teórico & 0 & 11 & 4 \\
3. Integração com serviços & 1 & 6 & 8 \\
Total & 3 & 23 & 19 \\
\hline
\end{tabular}


Especialidades Odontológicas) contribuem em parte para que a maioria das faculdades comece a se preocupar em preparar cirurgiões-dentistas com um perfil generalista, capazes, pelo menos razoavelmente, de trabalhar no SUS. Contudo, os sete coordenadores que elegeram a resposta mais abrangente, não fizeram referências às qualidades citadas no enunciado da alternativa - "perfil autônomo, crítico e reflexivo", no máximo comentando o perfil humanista desejado e, ainda assim, com poucas evidências. Deste modo, algumas das características importantes para o exercício da profissão parecem não ser suficientemente valorizadas e desenvolvidas. Tampouco houve justificativas ou evidências do fato de os egressos estarem realmente "familiarizados com os serviços de saúde", o que seria um importante indicativo dos esforços para a IES.

Com relação ao enfoque teórico, as escolas relataram ministrar seus cursos predominantemente buscando um equilíbrio no enfoque biológico e social, sendo poucas as que se baseiam no enfoque epidemiológico com ênfase na determinação social do processo saúde-doença. Observa-se, portanto, o indício positivo de que nenhum curso seguiria com o paradigma biomédico-clínico, ao que corresponderia um perfil de egresso tradicional. Contudo, constatou-se nas evidências relatadas uma atribuição de responsabilidade quase exclusiva às disciplinas de Saúde Coletiva pela concepção social deste enfoque teórico. É inegável a contribuição destas disciplinas, mas questionável a manutenção, ainda hoje, de outras disciplinas na visão estritamente biológica, até mesmo porque "os estudantes valorizam as diferentes áreas do conhecimento do mesmo modo que a maior parte de seus docentes" (Finkler, 2009, p.163). Desta forma, é também duvidoso que um curso consiga formar profissionais sob o enfoque teórico indicado, se este enfoque está restrito a poucos.

Já a questão que abordava diretamente a IES foi a que mais apresentou inconsistências entre as respostas eleitas e as justificativas e evidências apontadas, o que demanda cautela na análise. As inconsistências se devem, basicamente, ao conceito de serviços docente-assistenciais e de IES, que, apesar de constar por extenso no questionário, parece não ter sido sempre considerado ou não ser conhecido por todos, ou, ainda, ser confundido com outras atividades. Apenas três faculdades demonstraram indícios de alguma IES. As demais se referiram ao vínculo criado entre os cursos e os serviços por conta de convênios para o ressarcimento de atendimentos, de parcerias para campos de estágios, da presença de docentes que também são funcionários municipais ou estaduais, e de profissionais dos serviços que trabalham na escola. Porém, estes vínculos com o SUS não são indicativos de que o ensino-aprendizado esteja sendo desenvolvido sob suas diretrizes, em cenários reais de prática e conjuntamente com os profissionais dos serviços, gestores e usuários, co-participem tanto do ensino quanto do planejamento, execução e avaliação dos serviços.

De fato, percebe-se uma confusão conceitual no meio acadêmico e o uso indiscriminado de termos como IES, estágio docente-assistencial, estágio curricular supervisionado, estágio intra e extramuros, internatos, entre outros, de modo que novos nomes podem ser atribuídos a práticas já tradicionais, numa apenas aparente adequação às DCNs. Tome-se, como exemplo, o estágio curricular que as DCNs preconizam que seja desenvolvido sob supervisão docente, de forma articulada e com complexidade crescente ao longo do processo de formação, tendo uma carga horária mínima de $20 \%$ do total (Brasil, 2002).

No entanto, a Associação Brasileira de Ensino Odontológico define o estágio curricular como o "instrumento de integração e conhecimento do aluno com a realidade social e econômica de sua região e do trabalho em sua área [...] o atendimento integral ao paciente que o aluno de Odontologia presta à comunidade, intra e extramuros" (ABENO, 2002, p.39).

Mas, como afirmam Tumang, Rigolon e Gasparetto (2004), o estágio intramuros não contempla o contato do aluno com a realidade social, pois essa realidade é mascarada pela estrutura institucional que interfere nas relações. $O$ atendimento ao paciente onde ele vive é distinto do atendimento no espaço escolar que é familiar ao próprio aluno e que reproduz os seus próprios valores. No ambiente externo é que o papel social do estudante é transformado, quando ele se coloca frente aos desafios da população que vai atender (Werneck et al., 2007).

Porém, o fato de o estágio ser extramuros tampouco assegura a aderência às DCNs, pois não garante que haverá integração com o mundo do trabalho, não implica necessariamente na articulação com o SUS, nem no envolvimento crescente ao longo e desde o início da formação. Mas, para formar 
profissionais com o perfil adequado, os cursos precisam promover atividades práticas com estas características, em cenários de ensino diversificados. Isto exige sair das práticas profissionalizantes realizadas em clínicas de ensino de especialidades para as clínicas integradas e atividades extramurais em unidades do SUS, com graus crescentes de complexidade, bem como substituir os serviços próprios isolados da rede por serviços próprios completamente integrados, com mecanismos institucionais de referência e de contrarreferência (Morita, Kriger, 2004).

Indo além, o estágio supervisionado, na lógica da IES, pressupõe a supervisão das atividades do estudante tanto por docentes quanto por profissionais dos serviços. Esta preceptoria externa é um elemento pedagógico fundamental, visto que concebe o trabalho como fonte de saberes e de experiência (Werneck et al., 2007).

Estágios supervisionados em escolas, creches, asilos, hospitais, internato em saúde coletiva ou internato rural, embora possam ser bastante válidos sob alguns aspectos (Moimaz et al., 2008; Werneck et al., 2007; Medeiros Jr. et al., 2005; Werneck, Lucas, 1996), de um modo em geral não possibilitam o alcance dos objetivos das DCNs. Isto porque não é possível, por meio de atividades pontuais e isoladas no currículo, estabelecer-se um compromisso social, já que o envolvimento costuma ser de curta duração (Werneck et al., 2007). Além disto, a interação ativa do aluno com a população e com os profissionais deve ocorrer a partir de problemas reais, assumindo-se responsabilidades crescentes (Morita, Kriger, 2004). Portanto, é questionável também a realização destes estágios visando à IES somente ao final do curso, quando toda a formação prévia do estudante o preparou para uma atuação desarticulada das demandas dos serviços.

Quando hoje se menciona o termo IES, é preciso se ter em mente que as tentativas nesse sentido não são novas. Há um acúmulo de experiências cujos resultados já mostraram que a associação universidade-serviço-comunidade, juntamente com um programa de apoio, são as estratégias que mais proporcionam acumulação de recursos de poder entre os atores interessados em transformações, tanto na formação universitária, quanto na atuação dos serviços (Almeida, Feuerwerker, Llanos, 1999).

A estratégia de integração docente-assistencial (IDA), nas décadas de 1970 e 1980, foi a pioneira na articulação de cursos de medicina, enfermagem, odontologia e outros com os serviços. Apesar de terem contribuído de forma significativa para a construção do SUS, o seu impacto na formação profissional foi limitado, pois muitas das experiências inovadoras permaneceram isoladas nas universidades e também porque as relações estabelecidas com os serviços eram bastante verticais, considerados mais cenários que parceiros (Feuerwerker, 2002). Além disto, as relações entre os atores envolvidos davam-se apenas de forma bilateral, por conta da IDA (universidade/serviços), da extensão universitária (universidade/ comunidade) e da atenção primária à saúde (serviços/comunidade) (Albuquerque et al., 2008).

A Rede IDA foi um fecundo espaço de criatividade para gestar ideias e lideranças fundamentais no desenvolvimento do setor, tal como o Programa UNI, no início dos anos noventa, que considerava a comunidade sujeito de seu próprio destino, contando com dois parceiros: a universidade e os serviços. Sua proposta era construir estas parcerias ("integração ensino-serviço-comunidade") para a transformação da educação profissional, a reorganização dos serviços e para o fortalecimento da organização comunitária (Chaves, 1993).

A entrada dos projetos UNI na Rede IDA constituiu a Rede UNIIDA, que se construiu como um ator social, buscando influenciar as políticas públicas, como, por exemplo, no trabalho em torno da proposta das DCNs para as profissões da saúde (Feuerwerker, 2002). Vale, portanto, observar que as DCNs possuem, em seu âmago, os resultados acumulados das experiências prévias de integração "ensinoserviço- comunidade":

A formação do cirurgião-dentista deverá contemplar o sistema de saúde vigente no país [...] exercer sua profissão de forma articulada ao contexto social, entendendo-a como uma forma de participação e contribuição social [...] proporcionando condições para que haja benefício mútuo entre os futuros profissionais e os profissionais dos serviços, inclusive, estimulando e desenvolvendo a mobilidade acadêmico/profissional, a formação e a cooperação através de redes nacionais e internacionais (Brasil, 2002, p.10). 
Evidencia-se, portanto, que a concepção de integração "ensino-serviço-comunidade" que permeia este documento não confere com os conceitos e entendimentos expressos pelos coordenadores dos cursos, levantando indícios de que a real IES é ainda incipiente.

Uma análise mais aprofundada sobre esta realidade foi possível com o seguimento da pesquisa, para o que, tanto o curso que se revelou o mais tradicional quanto o curso aparentemente mais avançado foram escolhidos (Curso T e Curso A, respectivamente).

\section{Focando a integração "ensino-serviço" na prática: uma aproximação da realidade vivenciada em dois cursos de Odontologia}

O trabalho de análise qualitativa do novo PPP do Curso T evidenciou a preocupação principal com a adaptação do curso às DCNs. Uma das principais mudanças realizadas consiste na reestruturação do currículo com a integração das disciplinas profissionalizantes, por meio do trabalho multidisciplinar nas clínicas de complexidade crescente. Ainda hoje, as disciplinas pré-clínicas e clínicas deste curso possuem, cada uma, o seu próprio ambiente de ensino-aprendizagem. No novo currículo, as disciplinas do ciclo profissionalizante deverão atuar integradamente; no entanto, as disciplinas do chamado ciclo básico não foram pensadas sob esta mesma lógica, fato justificado pelo "modo ainda tradicional de organização burocrática e administrativa da instituição".

Outra ressalva se faz ao conceito de multidisciplinaridade, restrito ao trabalho conjunto de disciplinas apenas do curso de Odontologia. Experiências de ensino-aprendizagem multiprofissional não estão previstas, nem mesmo no estágio supervisionado extramuros onde atuam estudantes de diferentes cursos de graduação em saúde, uma das poucas atividades acadêmicas desenvolvidas nos serviços. Lá os estudantes permanecem durante um mês, no último período do curso, sob supervisão de um professor substituto, exercitando seu aprendizado clínico. As demais atividades desenvolvidas nos serviços estão limitadas a uma disciplina introdutória de saúde coletiva, que proporciona uma aproximação superficial com o SUS aos estudantes que nela se matriculam (por ser optativa), e a um estágio curricular em ambiente hospitalar. Os estudantes, no entanto, parecem sentir falta de uma aproximação do ensino com a realidade dos serviços, pois assim se manifestam:

"A gente tá aprendendo uma coisa que é totalmente correta, como no livro, e quando chega lá fora, como na experiência do posto de saúde assistindo um dentista, meu Deus do céu, é totalmente diferente!" (estudante 1, grupo focal, curso T)

"Isso aqui é um serviço público, né? Só que a gente trabalha de uma forma quase se fosse de uma forma particular. Se a gente for pro serviço público de verdade, num posto de saúde, aí você vê o que é!" (estudante 2, grupo focal, curso T)

O coordenador do curso afirma que tão logo o curso disponha de incentivos financeiros tentará equipar algumas Unidades Básicas de Saúde (UBS) para levar os estudantes aos serviços. Contudo, não há estratégias delineadas neste sentido.

Por todos estes aspectos, percebe-se que o Curso T pouco valoriza a IES e não a desenvolve: não há planejamento em comum com os serviços nas áreas de influência do curso, nem mesmo um serviço de referência e contrarreferência das clínicas da faculdade estruturado com o SUS. Não há previsão de um programa de integração docente-assistencial, nem um diálogo iniciado com os gestores dos serviços, estando a participação de profissionais da rede no ensino limitada à atuação clínica em um serviço de pronto-atendimento do curso. Os termos "saúde da família" e "controle social", por exemplo, constam uma única vez em todo o PPP, ainda que nele estejam inclusas as ementas de todas as disciplinas relacionadas à Saúde Bucal Coletiva. Portanto, resultam escassas as situações de ensino-aprendizagem pensadas na rede de saúde, envolvendo profissionais, usuários e gestores. É evidente que um novo currículo vai sendo aperfeiçoado concomitantemente com a sua implantação, e que as ausências aqui indicadas poderão vir a ser contempladas, mas, de qualquer maneira, o não-dito no PPP de alguma forma também diz sobre as escolhas, valores e possibilidades de cada curso. 
Uma segunda mudança curricular enfatizada diz respeito a uma maior importância em relação às temáticas da saúde coletiva. É possível perceber a valorização das diferentes áreas pela distribuição do tempo curricular entre elas (Figura 1); e, efetivamente, as disciplinas que estão diretamente relacionadas à saúde coletiva e aos serviços públicos passaram a ocupar, de 5,30\% no antigo currículo, 9,75\% do tempo da nova matriz curricular, devido à inclusão de quatro disciplinas de Saúde Bucal Coletiva ao longo da formação.

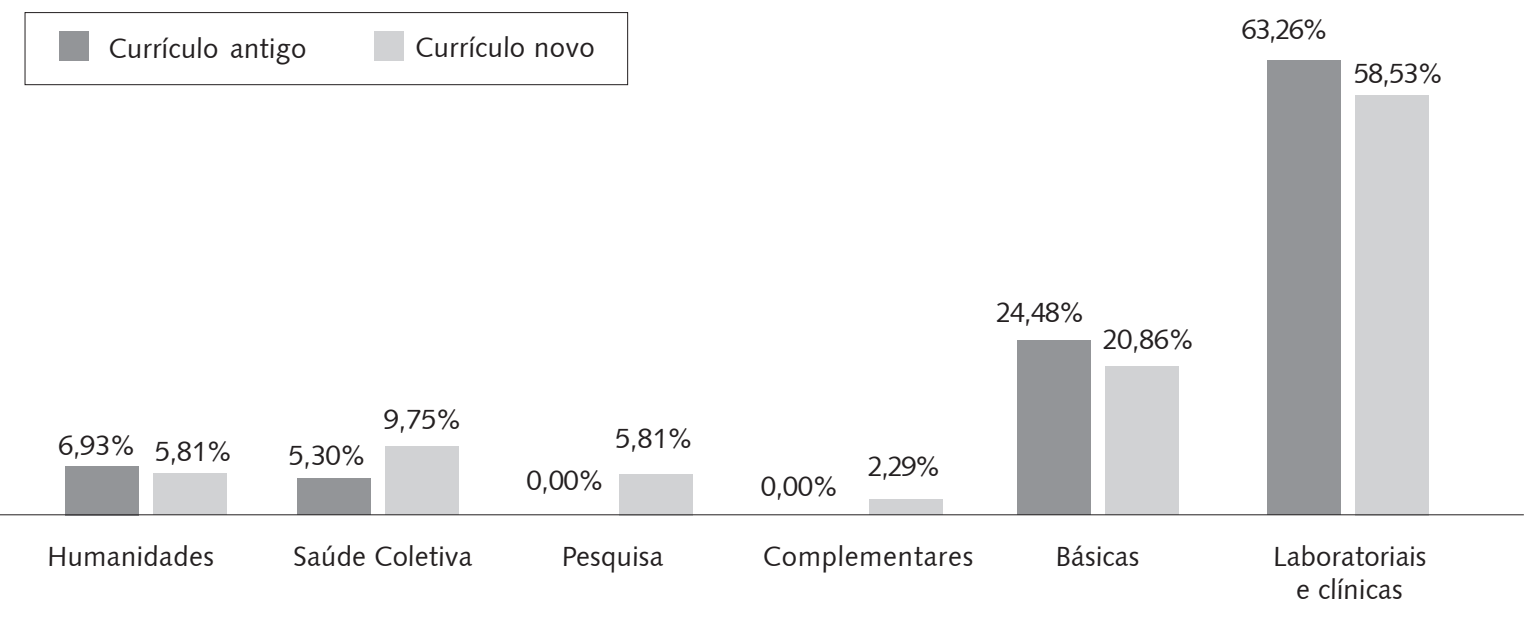

Figura 1. Distribuição da carga horária entre as disciplinas agrupadas por temas, nos currículos antigo e novo do Curso T

Contudo, o aumento da carga horária destinado à temática é um indicador limitado, uma vez que puramente quantitativo. A aparente redistribuição do tempo entre os temas curriculares se deve basicamente ao aumento no total de horas do curso. Isto fica evidente ao se observarem as disciplinas básicas, que ocupavam $24,48 \%$ do tempo, e que, no novo currículo, passaram a equivaler a $20,86 \%$, embora a redução tenha sido de apenas 15 horas-aula. Do mesmo modo, as disciplinas pré-clínicas e clínicas, que antes representavam $63,26 \%$ do total, apesar de terem sido aumentadas em número, agora constituem $55,53 \%$ do tempo curricular.

Assim, as mudanças propostas pelo novo currículo não são indicativas de um reequilíbrio entre o enfoque biológico/clínico hegemônico e o social/epidemiológico, ou de uma provável alteração do perfil do egresso. De acordo com a classificação de Almeida (1999), aperfeiçoada por Feuerwerker (2002), a reforma curricular em implementação neste curso se enquadra no plano mais superficial de mudanças na formação em saúde, caracterizada por algumas inovações pontuais, sem alteração da concepção tradicional de educação e da concepção biologicista em saúde, e, portanto, com uma provável reprodução das práticas hegemônicas nas duas áreas.

Já o PPP do Curso A levou a sério as DCNs, adequando-o às diretrizes a partir da convicção da necessidade de mudanças nas concepções e estratégias curriculares, e não apenas pela demanda externa ao curso. Esta motivação está muito relacionada aos seus dirigentes, devido a sua formação e experiências prévias e a sua capacidade de liderança e articulação de um grupo docente que soma forças no alcance das metas instituídas no novo currículo. As principais ênfases do PPP recaem sobre a necessidade de mudanças nas concepções acerca do processo ensino-aprendizagem, as inovações metodológicas que buscam a integração curricular, o trabalho multidisciplinar e a interatividade dos estudantes. 
A integração curricular foi possível pela união dos antigos ciclos básico e profissionalizante em quatro eixos estruturais, transversais e multidisciplinares. Os estudantes são inseridos precocemente nos contextos profissionais: no primeiro semestre eles já estão presentes nas UBS, sendo integrados às Equipes de Saúde da Família (SF) como observadores (com envolvimento crescente ao longo do curso), e, no segundo semestre, na clínica odontológica da faculdade. Essa entrada precoce nos diferentes cenários de ensino-aprendizagem é uma das questões que reforçam a valorização da interatividade acadêmica, também percebida quanto às inovações em termos de metodologia de ensino: a problematização vem sendo empregada no curso como o referencial educativo para as atividades de promoção de saúde realizadas no contexto da SF. No momento da pesquisa, os alunos do último ano utilizavam o PBL em uma das quatro disciplinas, mas a intenção era de capacitar um maior número de docentes para o seu emprego e utilizá-lo também como referencial filosófico-pedagógico do curso.

Outra questão evidenciada relacionava-se à preparação do estudante para atuar no mercado de trabalho, tanto público quanto privado. A ênfase na saúde coletiva e nos serviços públicos de saúde pode ser confirmada pela quase triplicação da carga horária atribuída a estas temáticas em relação ao currículo anterior (Figura 2).

Currículo antigo Currículo novo

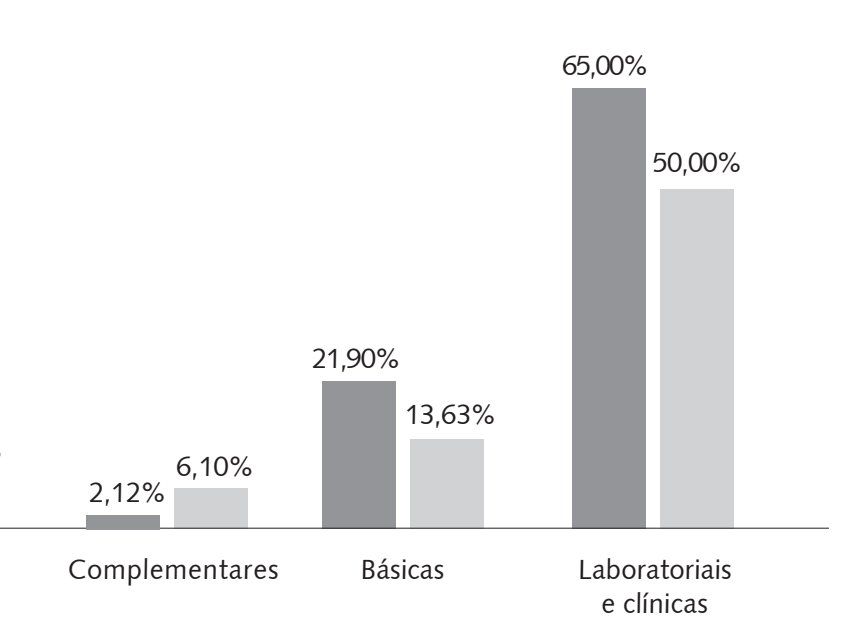

Figura 2. Distribuição da carga horária entre as disciplinas agrupadas por temas, nos currículos antigo e novo do Curso A

Ainda que o número de horas total do curso tenha sido um pouco ampliado, uma melhor distribuição do tempo dedicado a cada área foi possível pela integração das disciplinas básicas, laboratoriais e clínicas do antigo currículo, diminuindo significativamente a proporção de suas cargas horárias em favor das demais temáticas.

Há, também, outros indicadores, desde a missão da instituição universitária até os diferentes cenários de aprendizagem no SUS com graus crescentes de complexidade, que confirmam a importância da saúde coletiva no curso, revelam sua consciência pela responsabilidade social e a valorização da IES. Contudo, esta integração é ainda parcial: o sistema de referência e contrarreferência entre a escola e o SUS funciona apenas para algumas das especialidades clínicas, sendo os pacientes oriundos de demanda livre atendidos no curso sem nenhuma integração com a rede. Além disso, os estudantes atendem clinicamente as famílias da ESF na clínica do próprio curso, embora o PPP preveja "que as Equipes de Saúde Bucal acompanharão os trabalhos dos acadêmicos como preceptores". Assim, o atendimento clínico reabilitador continua desvinculado do mundo do trabalho, isolado da interação com os profissionais da rede, da gestão do sistema e do seu controle social. 
Os docentes relatam dificuldades nesta integração, experimentadas desde o planejamento do novo currículo, pela pequena participação da gestão dos serviços nas oficinas da reforma curricular, e, sobretudo, na realização dos estágios em campo. Questões administrativas com a Secretaria Municipal de Saúde e alguns problemas de relacionamento junto à coordenação de Saúde Bucal são apontados como entraves significativos para uma maior IES, mas consideram estar avançando ao longo do tempo. Se retomarmos, aqui, o conceito do "quadrilátero para a formação em saúde" (Ceccim, Feuerwerker, 2004), ficam evidenciadas as lacunas que dificultam a reformulação das práticas que precisam estabelecer relações orgânicas entre si.

Retomando a classificação de Almeida (1999) aperfeiçoada por Feuerwerker (2002), a reforma curricular neste curso se enquadra no segundo plano de mudanças na formação em saúde, correspondente à concepção humanista de educação e ao conceito ampliado de saúde. A instituição, assim, progride na busca de alternativas às práticas hegemônicas, considerando o social em direção às práticas de reflexão crítica. Mas ainda precisa investir em uma maior integração ensino-gestão-atençãocontrole social e no trabalho multiprofissional e interdisciplinar, para que a profundidade das mudanças possa ser considerada efetivamente como uma reforma, e não apenas como inovações.

A classificação do Curso A, considerado o mais avançado dentre os cursos pesquisados, como estando no segundo plano de profundidade em relação às mudanças no processo de formação em saúde, é indicativa de que os cursos de Odontologia ainda têm um longo caminho a percorrer em direção a mudanças mais profundas que sejam capazes de promover uma verdadeira transformação social. Segundo Feuerwerker (2002), os cursos precisariam investir não só no trabalho multiprofissional interdisciplinar e na efetiva integração IES, mas também na atuação inter-setorial, na efetiva articulação biopsicossocial, no controle social, na associação entre estudo e trabalho, e na transformação do poder em autoridade compartilhada. Assim, as mudanças poderiam ser não apenas técnicas e sociais, mas também políticas, o que corresponderia ao plano de maior profundidade de mudanças.

Considerando-se que os resultados indicaram a praticamente inexistente integração do mundo da escola com o mundo do trabalho em saúde em uma instituição (curso T) e o processo apenas incipiente na outra (curso A), ficam evidenciadas as limitadas ações dos cursos de Odontologia quanto à integração ensino-gestão-atenção-controle social, bem como alguns dos desafios àqueles que pretendem avançar no processo de mudanças da formação profissional.

\section{Considerações finais}

Todos os esforços prévios de IES em Odontologia tiveram pouca sustentabilidade, pois sempre dependeram de uma adesão ideológica de docentes e estudantes e da voluntariedade dos professores, mais do que do apoio institucional e da participação do quadro docente como um todo (Morita, Kriger, 2004).

Recentemente, no entanto, o apoio institucional começa a se fazer presente por meio de políticas públicas e de programas, pelo menos nos 32 cursos de Odontologia que fazem parte das 67 instituições selecionadas para o PET-Saúde em 2009. Este momento político favorável vem ao encontro dos resultados desta pesquisa, reveladores de uma apenas incipiente integração entre os cursos de Odontologia e o SUS, no momento imediatamente anterior ao lançamento do PET-Saúde. Tal investimento de recursos e esforços no fomento desta integração revela-se promissor, pois nossas mudanças curriculares serão socialmente tão relevantes quanto forem nossos avanços no processo de integração ensino-gestão-atenção-controle social.

Aproximar-se dos serviços de saúde tem de ser uma opção consciente e oficial de cada um dos cursos. Esta aproximação deve ser conduzida na forma de uma proposta-convite aos serviços, para que o local do desenvolvimento das atividades dos estudantes passe a ser o mesmo que os profissionais enfrentam no cotidiano de suas práticas. Nele, o sujeito do aprendizado não deve ser visto como mãode-obra (Werneck, Lucas, 1996), pois a contrapartida do ensino para os serviços deve se dar na colaboração para a reorientação da prática de atenção à saúde, de um modelo tecno-assistencial hegemônico, centrado na produção de procedimentos, para um modelo centrado nas necessidades 
sociais. Portanto, os cursos não devem impor esquemas preconcebidos que possam prejudicar a percepção da realidade ou predefinir propostas de trabalho, mas adequar as atividades demandadas pelos municípios aos objetivos da formação profissional.

A integração poderá acontecer quando existir, tanto para a escola quanto para a rede, uma intencionalidade complementar e convergente, com objetivos comuns e peculiares, capazes de constituir espaços pedagógicos com vivências que possibilitem, para ambas, ganhos reais. Neste contexto, a realidade que ensina é, ao mesmo tempo, objeto do aprendizado, gerando reflexão, crítica e autocrítica, constituindo-se no substrato fundamental à formação pessoal e profissional do acadêmico (Werneck et al., 2007). Mas a integração só acontecerá de fato quando pensada longitudinalmente, desde o seu início da graduação, de modo que, ao final de cinco anos, o formando se sinta familiarizado e comprometido com o SUS, capacitado a atuar na transformação do seu modelo de atenção, de gestão e de controle social.

Sabe-se que nada disto é tarefa simples, pois exige uma organização de coletivos centralmente comprometidos com a dimensão pedagógica das práticas de ensino, de atenção à saúde, de gestão setorial e de controle social, e com a defesa do interesse público na política de saúde e de educação nacionais. Contudo, é o caminho que precisa ser trilhado em cada curso da área da saúde, despertando sensibilidades, reflexão e diálogo, promovendo negociações, aproximações, rearranjos, superações, enfim: um processo que precisa ser calcado na certeza de que a construção de cidadania e da democracia dependem fundamentalmente do sucesso no trabalho intersetorial da saúde e da educação.

\section{Colaboradores}

Mirelle Finkler responsabilizou-se pela produção da pesquisa e pela elaboração do artigo. João Carlos Caetano e Flávia Regina Souza Ramos responsabilizaram-se pela orientação da pesquisa e pela revisão crítica do artigo.

\section{Referências}

ABENO. Diretrizes da ABENO para a definição do estágio supervisionado nos cursos de Odontologia. ABENO, v.2, n.1, p.39, 2002.

ALBUQUERQUE, V.S. et al. A integração ensino-serviço no contexto dos processos de mudança na formação superior dos profissionais da saúde. RBEM, v.32, n.3, p.356-62, 2008.

ALMEIDA, M.J. Educação médica e saúde: possibilidades de mudança. Londrina: UEL, 1999.

ALMEIDA, M.; FEUERWERKER, L.; LLANOS, M. (Orgs.). A educação dos profissionais de saúde na América Latina: teoria e prática de um movimento de mudança. São Paulo: Hucitec, 1999.

BRASIL. Ministério da Saúde. Portaria Interministerial n 1.802, de 26 de agosto de 2008. Institui o Programa de Educação pelo Trabalho para a Saúde - PET-Saúde. Diário Oficial da União, Brasília, 26 ago. 2008. Seção 1, p.27.

Ministério da Saúde. Ministério da Educação. Programa Nacional de

Reorientação da Formação Profissional em Saúde - Pró-Saúde: objetivos, implementação e desenvolvimento potencial. Brasília: Ministério da Saúde, 2007. 
BRASIL. Ministério da Saúde, Ministério da Educação. Pró-Saúde: Programa Nacional de Reorientação da Formação Profissional em Saúde. Brasília: Ministério da Saúde, 2005.

. Ministério da Saúde. Secretaria de Gestão do Trabalho e da Educação em Saúde. Aprender SUS: o SUS e as mudanças na graduação. Brasília: Ministério da Saúde, 2004.

Ministério da Educação. Conselho Nacional de Educação. Câmara de Educação Superior. Resolução CNE-CES n. 3, 2002. Institui as Diretrizes Curriculares Nacionais do Curso de Graduação em Odontologia. Diário Oficial da União, Brasília, 4 mar. 2002. Seção 1, p.10.

CECCIM, R.B.; FEUERWERKER, L.C.M. O quadrilátero da formação para a área da saúde: ensino, gestão, atenção e controle social. Physis, v.14, n.1, p.41-65, 2004.

CHAVES, M.M. A Odontologia no componente acadêmico dos projetos UNI. Bol. Inf. CEDROS, v.2, n.4, 1993. Disponível em: <http://www.ibiblio.org/taft/cedros/ portugues/newsletter/n4/dentacde.html>. Acesso em: 23 jun. 2009.

FEUERWERKER, L. Além do discurso de mudança na educação médica: processos e resultados. São Paulo: Hucitec, 2002.

FINKLER, M. Formação ética em Odontologia: realidades e desafios. 2009. Tese (Doutorado) - Curso de Pós-graduação em Odontologia, Universidade Federal de Santa Catarina, Florianópolis. 2009.

HADDAD, A.E. et al. A aderência dos cursos de graduação em Odontologia às Diretrizes Curriculares Nacionais. In: BRASIL. Ministério da Saúde. Ministério da Educação. A aderência dos cursos de graduação em Enfermagem, Medicina e Odontologia às diretrizes curriculares nacionais. Brasília: Ministério da Saúde, 2006. p.119-52. (Série F, Comunicação e Educação na Saúde)

LAMPERT, J. Tendências de mudanças na formação médica no Brasil. São Paulo: Hucitec, 2002.

MEDEIROS JR., A. et al. Experiência extramural em hospital público e a promoção da saúde bucal coletiva. Rev. Saude Publica, v.39, n.2, p.305-10, 2005.

MOIMAZ, S.A.S. et al. Atividades extramuros na ótica de egressos do curso de graduação em odontologia. ABENO, v.8, n.1, p.23-9, 2008.

MORITA, M.C.; KRIGER, L. Mudanças nos cursos de Odontologia e a interação com o SUS. ABENO, v.4, n.1, p.17-21, 2004.

RAMOS, F.R.S.; PADILHA, M.I.C.S. Formação profissional e políticas de saúde- cenários em transformação? In: COLÓQUIO LUSO-BRASILEIRO SOBRE QUESTÕES CURRICULARES, 3., 2006, Braga. Anais... Braga, 2006. p.102.

TUMANG, A.J.; RIGOLON, C.J.; GASPARETTO, A. Ensino/serviço/comunidade: as experiências do estágio supervisionado. In: TERRADA, R.S.S.; NAKAMA, L. (Orgs.). A implantação das diretrizes curriculares nacionais de odontologia: a experiência de Maringá. São Paulo: Hucitec, 2004. p.101-28.

WERNECK, M.A.F.; LUCAS, S.D. Estágio supervisionado: uma experiência da integração ensino/serviço de saúde bucal. Arqu. Cent. Est. Curs. Odont., v.32, n.22, p.95-108, 1996.

WERNECK, M.A.F. et al. Nem tudo é estágio: contribuições para o debate. Cienc. Saude Colet., v.15, n.1, p.221-31, 2007. Disponível em: <http://www.scielo.br/ scielo.php? pid $=$ S1413-81232010000100027\&script $=$ sci arttext\&tlng $=p t>$. Acesso em: 17 jun. 2009. doi: 10.1590/S1413-81232010000100027. 
FINKLER, M.; CAETANO, J.C.; RAMOS, F.R.S. Integración "enseñanza-servicio" en el proceso de cambio en la formación profesional en Odontología. Interface - Comunic., Saude, Educ., v.15, n.39, p.1053-67, out./dez. 2011.

Este trabajo intentó evaluar la integración de las licenciaturas de Odontología con la red pública de salud. Para eso, se toman los datos recolectados con metodología cualitativa en un estudio de caso con 15 cursos, articulados con un referencial teórico para el análisis de los cambios en la formación en salud, en lo cual la integración "enseñanza-servicio" es concebida como enseñanza, gestión, atención y control social. Los resultados indicaron una confusión conceptual acerca del tema, vínculos con el sistema de salud distintos de la integración y la prácticamente inexistente integración enseñanza-atención-gestión-control social, o como máximo, un proceso incipiente y en construcción. Se puede así considerar que los cursos de Odontología brasileños necesitan avanzar en las alianzas y en las acciones estratégicas con base en la educación permanente en salud, a fin de que los nuevos cambios curriculares sean efectivamente capaces de colaborar con el Sistema Único de Salud.

Palabras clave: Servicios de integración docente asistencial. Educación superior. Enseñanza. Escuelas de Odontología. Personal de Odontología. 